\title{
Scientific Writing: Following Robert Boyle's Principles in Experimental Essays -1704 and 1998 ${ }^{1}$
}

\author{
Inés Lareo and Ana Montoya Reyes \\ University of Coruña and Cesuga-University College \\ ilareo@udc.es / anamontoyaes@yahoo.com
}

\begin{abstract}
Science and scientific method have evolved in parallel with changes in philosophical ideas. One aspect of the discipline affected by these changes is the way in which scientists' results should be shown to the world. However, it was not until the second half of the 17th century that the first recommendations or guidelines for reporting scientific discoveries appeared. The Royal Society became the first institution to concern itself with the form this new discourse should take.

The aim of this paper is to analyse the linguistic evolution experienced by two pieces of scientific writing and to examine to what extent the two texts follow the recommendations of Robert Boyle and the Royal Society concerning the patterns scientific discourse should observe. Two texts were selected for the task, one published at the beginning of the 18th century, the other at the end of the 20th. For the purposes of comparison, the texts analysed are from the same discipline and both report an experiment on Optics. .
\end{abstract}

\section{Introduction}

Our aim in this paper is to compare the language and linguistic structure of two experimental essays, published in 1704 and 1998, to find out if the main features of the experimental essay, a new expository form established during the Early Modern English period and promoted by the Royal Society (Atkinson, 1999; Gotti, 2001, 2003, 2005; Moessner, 2006, 2007, forthcomingA, forthcomingB; Valle, 1999), are present. A statistical study will not 
be undertaken owing to the difference in length between the texts analysed. Nevertheless the time span, of almost 300 years, should be wide enough to ascertain if Robert Boyle's principles have been preserved or if, instead, scientific discourse today is reported in a substantially different way. Two experiments based on the same discipline, Optics, have been selected for the purposes of comparison. The first text was written by one of the most important scientists of the Enlightenment period; the second, by a modern research team, and was published in 1998 in a well-known journal of the Optical Society of America, Applied Optics.

In the first part of this study we present a brief overview of the concept of "science" (section 2), the inception of the scientific text and the development of scientific language from the Middle Ages onwards (section 3). The second part contains a comparative analysis of different passages from both essays (section 4). The earlier text is taken from Newton's Opticks: or a Treatise of the Reflections, Refractions, Inflections and Colours of Light (first edition), published in 1704, while the more recent one is an article about an experiment published in Applied Optics in 1998, "Experimental study of the effects of a six-level phase mask on a digital holographic storage system". Our aim, as mentioned above, is to analyse and compare the discourse used in both cases and propose some conclusions about how scientific writing has evolved over the last three hundred years.

\section{The Concept of Science from the End of the Middle Ages to the $\mathbf{2 0}^{\text {th }}$ Century}

Science as a human pursuit has been constrained down through history by the different schools of thought and belief prevailing at the time of its definition. Disciplines were included or forbidden according to the limits placed on the term science in consequence of these shifting circumstances. Etymologically, the word comes from the Latin scientia 'knowing' and until the middle of the $19^{\text {th }}$ century (1840) it referred to what we know today as natural philosophy. An example of this is found in the book Principia Mathematica Philosophiae Naturalis (The Mathematical Principles of Natural Philosophy), published in 1687 by Newton, whom contemporary scientists thought of as a philosopher.

Social context has marked and limited the development of science; indeed, we can hardly speak about scientific progress in Europe until the $16^{\text {th }}$ century. One aspect of this constraint is the influence of religion on science. Even though in the classical age science was synonymous with philosophy, during the Middle Ages it became more closely associated with religion: physics was blended with ideas from Scripture, while the holy books themselves were used as talismans and their text to contain some arcane significance. Meanwhile, however, still within the field of science, there was a sector whose characteristics had more in common with the realm of magic and the otherworldly than with more earthly matters. To take one obvious example, the alchemist was a highly admired and frequently called-upon figure (though not altogether consistently so) in the $14^{\text {th }}$ century. The weight of religion, however, transformed alchemy into an illicit activity; chemistry, by direct association, went the same way and until the $17^{\text {th }}$ century was named as one of the 
"seven devilish arts". Consequently, the first works produced by alchemists and chemists, the first examples of experimental science, were excluded from the field of science until that time.

It was during the Renaissance that modern science began. With all traditional knowledge called into question, under the new concept of science efforts became focused on the systematic observation and verification of hypotheses, starting from controlled experiments. Francis Bacon was the main proponent of this new method, consolidated in the scientific field around the middle of the $17^{\text {th }}$ century ${ }^{2}$. Owing to this methodology, a scientific epistemology based on observation was developed and a new form of presenting the process emerged: the experimental essay (Birch, 1756; Gotti, 1996; Moessner, 2006).

In England, as elsewhere, modern science came into conflict with medieval theological attitudes $^{3}$. The scientific revolution reached its highest point with the foundation of societies devoted specifically to science, such as the Spalding Gentlemen's Society, founded in 1710 "for the supporting of mutual benevolence, and their improvement in the liberal sciences and in polite learning' (Honeybone, 2005; Spalding Gentlemen's Society, 2007); or the Royal Society, whose beginnings can be traced back to 1645 (Sprat, 1722: 53; Birch, 1756: 1). In 1660 the members of the Royal Society decided to "found a college for the promoting of physico-mathematical experimental learning", the meetings of which were endorsed by the king (Birch, 1756: 3-4). This moment marked the beginning of the institutionalisation of scientific investigation. The Royal Society and the British Association for the Advancement of Science (BA), established in 1831 (BA, 2007), stood out from the rest, despite their rejection by numerous theologians and clergymen. Indeed, while the power wielded by the Church, the Protestant as well as the Roman Catholic, might sometimes have acted as deadweight on scientific advance, we should also bear in mind that many well-known scientists responsible for new scientific research and discoveries were also members of the clergy (Silvestre II, Gregor Mendel, Nicolás de Cusa, Teilhard de Chardin, etc).

Materialist science finally came of age in the $18^{\text {th }}$ century, weaned on Cartesian philosophy and Newtonian scientific discovery, attempts both to explain the natural process on the basis of physical and chemical evidence. The evolution of ideas concerning scientific methodology and the great transformation of knowledge during this period paved the way for the emergence of the modern concept of science.

\section{Scientific Language}

A direct consequence of the changes in the concept of science and the development of the scientific community described above was the evolution of scientific writing. The old method of speculating and reaching conclusions through introspection gave way to one of objective empiricism, and the Royal Society called for changes in the presentation and publication of scientific discoveries made in this way. The new mode of showing and sharing new findings by scientists was the experimental essay, credited by some to Robert Boyle (eg. Gotti, 2001, 2003, 2005; Moessner, 2006). Though over time the conventions 
for this kind of writing have changed, an evolutionary continuum is discernible; after all, throughout history scientists have always argued and innovated their theories in the light of the work of their predecessors.

In the case of England, before the $16^{\text {th }}$ century most contemporary scholarship was written down in Latin or other languages, but with no translation into English. From that moment on, however, with the standardisation of the vernacular and its consolidation as the language of a nation, English began to be seen as a suitable medium for expressing scientific knowledge. Nevertheless it was not until the end of the $17^{\text {th }}$ century that both nativelanguage production and English translations of classical works actually began to appear (Gotti, 2005).

As mentioned before, the foundation of scientific societies compelled scientists to change the way in which experiments were presented so that not only members of the scientific community but also the inexperienced reader would be able to repeat them by following the same steps. The first serious attempt to define the content and style of scientific writing was made by the Royal Society in 1728, when they included the following stylistic indications in Article IV of Chapter V of its statutes (Gotti, 1992: 336):

In all Reports of Experiments to be brought into the Society, the Matter of Fact shall be barely stated, without any Prefaces, Apologies, or Rhetorical Flourishes, and entered so into the Register-Book, by order of the Society.

But Robert Boyle also played an important role in the evolution of scientific writing (Gotti, 1996, 2001; Hunter, 2007). Fulton (1932: 78) has highlighted the contribution of the scientist, describing Boyle's undertaking "to establish science as an integral part of the intellectual life of ordinary men". He encouraged scientists to write in a language that their contemporaries could understand, and he undoubtedly did more than anyone of his time to make scientific methodology part of the intellectual equipment of educated men. For instance, his Proëmial Essay, published in 1661, lists some of the features an experimental essay should have: among them, the avoidance of rhetorical embellishment, the use of short expressions, or avoiding the use of loan-words (Boyle, 1744: 192-204). This is precisely the pattern followed in Newton's experiment. What is particularly significant is Newton's decision not to use any mathematical descriptions in this book, a move interpreted by some researchers as a way of bringing science closer to the non-scientist reader (Banks, 2005: 70) (see appendix 1).

These rough guidelines and other tips given by Boyle in his works are expanded by Gotti (1996: 58-68, 2001: 223-237, 2003: 227-241, 2005: 173-186). According to Gotti, one of the features of experimental essays is brevity, but this brevity of form does not imply brevity in the exposition of the subject. On the contrary, experiments are usually reported in full, furnishing the reader with all the minutest details. The aim of such a report is, after all, to make it possible for the experiment to be repeated, making the precision of the description an important factor. Gotti has analysed some of Boyle's works to produce the following list of compositional indications: 
- Brevity: "sentences should be as concise as possible with no space given to unnecessary details".

- Lack of assertiveness: "there is no need for the author to arrive at definite conclusions or to systematise the results obtained". Scientists, therefore, should report the data as they are observed, present only the bare facts.

- Perspicuity: rhetorical embellishment should be avoided. The function of experimental writings is to "provide information in as clear a way as possible".

- Simplicity of form: "use of simple verb-forms and sentence-constructions". The voice most commonly used in $17^{\text {th }}$ century experimental essays was the active, thus highlighting the role and importance of the scientist and his/her function as subject. Nevertheless, the passive voice could be employed to underline unexpected results or to report how certain procedures were carried out.

- Objectivity: use of modal auxiliaries and verbs like seem and appear to show the author's uncertainty. Such an attitude makes it easier for the reader to see the scientist as a reliable person and as a witness to the events reported.

Considering that the guidelines for composing scientific works, namely experimental essays, were proposed by Boyle in the $17^{\text {th }}$ century, we can assume that prior to that date scientific writings did not follow any established pattern. The survival of the experimental essay genre, therefore, owes much to the rapid rise and diffusion of scientific journals dating from that time. Scientific writings in general, and experimental essays in particular, are highly normalized texts; nowadays, indeed, the scientific community has at its disposal a whole range of handbooks describing the conventions for producing texts of this type (Shulman, 1996; Perelman et al., 1997; Peat et al., 2002; Ebel, 2004; Tischler, 2006; Day, 2006).

Although the definition of the word "experiment" has changed since the beginning of the experimental essay, from any made or done thing to the testing of a theory or claim (Bazerman, 1988: 65), the aims of scientists past and present when reporting their experiments remain the same: to explain the procedures followed and the results obtained. Nevertheless, two important differences between early scientific texts and those written today are clear: the use of specialised language and the question of style.

In the following section we will see how at the beginning of the $18^{\text {th }}$ century both language and style seemed closer to a colloquial register, in keeping with attitudes to the discipline in society at the time. The purpose of science and scientists was to spread scientific knowledge, but not in order to achieve personal recognition. Scientific writing, based on this understanding, should be as clear and accurate as possible in order to facilitate the reproduction and verification of the experiment (Bazerman, 1988; Gotti, 2005). Nowadays, meanwhile, this kind of writing is the almost exclusive preserve of a closed community of trained scientists. Texts are produced by scientists professionally dedicated to interpreting data, attending conferences and submitting articles to specialist journals. Their main purpose is not so much to be understood by a general public but to be as accurate as possible.

Another outstanding feature of this type of discourse is its continuous quest for 
terminological coherence in order to avoid ambiguity. This attitude extends not only to terminology but to the overall conventions of scientific language, assumed by the scientific community generally in the interests of accuracy and clarity.

Specific changes in scientific as well as in general language have already been pointed out by Atkinson (1999), Biber and Finegan (1997), Moessner (2006), Rissanen (1999) and Valle (1999). Among them:

- The use of articles: the rules were less precise in the $17^{\text {th }}$ century

- The use of complex relative markers: markers such as wherein were more commonly used by earlier writers

- Changes in the style of written language: writing became more informative

- Increase and change in the use of passive constructions: the high number of passive constructions found in $20^{\text {th }}$ century texts has been explained by Biber and Finegan (1997) as a result of the shift from non-impersonal to impersonal style.

Although the avoidance of subordination is looked on as a feature of Present-Day English (PDE) specialised texts, the same strategy was found slightly less frequently in the $17^{\text {th }}$ century texts. Nevertheless, the aim of this paper is not to survey all the differences observed in scientific writing but to compare the linguistic features of two written experiments. The following section presents an analysis of the selected texts, taking the features of the experimental essay extracted from Boyle's writings by Gotti (1996, 2001, 2003, 2005) as its starting point.

\section{Analysis of Data}

The fragments selected for this analysis have been taken from the first edition of one of Newton's masterpieces, Opticks: a treatise of the reflections, refractions, inflections, published in 1704 (experiment 4) ${ }^{4}$; and from a modern study, "Experimental study of the effects of a six-level phase mask on a digital holographic storage system", published in Applied Optics in $1998^{5}$. We have chosen these two texts because both are experiments in optics produced at very different moments in history: from the socio-historical perspective, on the one hand, and from that of the linguistic status of the English language, on the other.

Newton's text, printed approximately 300 years ago, has been selected because of the historical relevance of its author. His influence on $18^{\text {th }}$ century science and on the Royal Society was crucial: his assumption of the presidency in 1704 heralded the beginning of a new era for the society, while the impact of his theories is still felt in science down to this day (Hall, 1981; Bunch and Hellemans, 2004: 195-229; Shapiro, 2004). Written between 1675-1687, but not published until 1704, the experiment selected was included in one of the first scientific books ever written in English; Halliday and Martin (1993: 57) use extracts from the same work to register the birth of scientific English.

The selection criteria applied to the modern text were as follows: written at the end of 
the $20^{\text {th }}$ century; published in a well-known journal ${ }^{6}$; and describing an experiment in optics. A comparison will show the extent to which Boyle's principles were followed in each of our experimental essays.

Our analysis has a binary structure: the first section deals with the features of the experimental essay listed by Gotti (2001) (section 4.1); the second then examines the social influences observed in both texts as a result of the evolution of the concept of science itself and changes in graphical and layout conventions (4.2).

\subsection{Evolution of the experimental essay}

The first component of our analysis is the main features of Early Modern English experimental essays, as extracted by Gotti (2001: 224-237). Robert Boyle and the Royal Society laid down some of the principles this type of discourse should observe, such as conciseness, shortness and simplicity of style (among others, listed in full in section 3). Boyle's principles were classified by Gotti as follows: brevity, lack of assertiveness, perspicuity, simplicity of form and objectivity. We have analysed our texts in terms of each of these characteristics in order to see, firstly, if they were present in Newton's experiment, as he was a Royal Society member; and, secondly, if they have survived down to the present or how they have changed.

Brevity is the first principle mentioned by Gotti, according to which sentences should be concise and precise (2001: 224). Having examined both experiments, we find that this is most certainly true of Newton's text. His sentences are clearly shorter and more concise than those in the modern text, as seen from examples (1) and (2):

(1) So then, by these two Experiments it appears that in equal Incidences there is a considerable inequality of Refractions. (Appendix 1: lines 18-20)

(2) From these experimental results one can conclude that having a phase mask in the $4 f$ holographic system yields no improvement to the system dynamic range despite the difference in which object-beam energy was distributed at the Fourier plane. An explanation for these unexpected results is that these holograms are stored not only at the Fourier plane but in the entire volume encompassed by the reference beam. (Bernal et. al., 1998: 2097)

In the modern text, conciseness is achieved by the use of compound nouns. This compounding strategy would appear, then, to be more productive nowadays than in eModE. In fact, Newton uses only one compound noun (see example (3)), in contrast to the higher number of occurrences found in the modern text (see example (4), taken from Appendix 2):

(3) Window-shut (Appendix 1: p. 22, line 2)

(4) six-level (sample 2: line 5); dynamic-range (sample 2: lines 7-8); object-reference (sample 2: line 9); bit-error (sample 2: line 10); object-beam (sample 2: line 12); chrome-on-glass (sample 3: line 1); two-dimensional (sample 3: line 2). 
The second feature is lack of assertiveness. This characteristic is achieved by reporting only the plain facts and excluding the author's opinions about the data presented. The exposition of facts might therefore be said to be the main function of experimental essays since the purpose of this type of writing is to show the process followed to achieve a given result. Its object is to report all the steps taken in order to allow the reader to repeat the experiment, not to provoke a discussion. When Francis Line criticised Newton's work, for example, Newton responded by setting out in much greater detail the methodology followed and the conditions in which the experiments had been carried out, and challenged Line to repeat them faithfully (Bazerman, 1988: 69, 117). Samples (5) and (6) illustrate the use of this narrative strategy in both texts:

(5) In this Situation of the Prism viewing through it he said hole, I observed the length of its refracted Image to be many times greater than its breadth [...] (Appendix 1: p. 23, lines 6-8)

(6) The molar dopant concentration was $0.02 \%$, and the absorptivity of the crystal at a wavelength of $514.5 \mathrm{~nm}$ was $0.8 \mathrm{~cm}^{-1}$. (Appendix 2: sample 3, lines 22-24).

But this principle of lack of assertiveness, while common to both texts, is not observed in the introduction of the PDE experiment. There the authors have included their opinion about the advantages of using "two-level phase masks" and of storing at the Fourier transform plane.

The third feature cited by Boyle is perspicuity (1744: 195). Gotti interprets this term as the rejection of unnecessary rhetorical devices, so common in literary texts. Such an attitude was considered necessary in scientists in their discourse since their language had to be more plainly referential. The principle of clarity was achieved through the following: firstly, the absence of obscure language that could complicate the understanding of the theories being explained; secondly, the use of a specialized terminology in English, instead of foreign words or "exotic terms", as Boyle calls them (1744: 196); and thirdly, the absence of polysemic words that could make a text ambiguous.

Basically, therefore, rhetorical devices or literary style and the use of non-referential words were to be avoided (Gotti, 2001: 228), particularly if they produced ambiguity or made the text confusing. Shapin (1984: 495) says that "this plain, puritanical, unadorned style was identified as functional" and that "it served to exhibit the philosopher's dedication to community service rather than to his personal reputation". Indeed, even though according to Bazerman (1988: 15) "Newton emerged in the forefront of actual innovation in rhetorical practice", we have found no rhetorical flourishes, such as metaphors or the use of first or second-person plural pronouns, in the experiment analysed here.

The fourth feature is simplicity of form. According to Gotti (2001: 232) this consists of using a plain style characterised by simple verb forms and the active voice. Gotti's (2003, 2005) and Moessner's (2006, forthcomingA) opinions on this question differ from that of Halliday and Martin (1993), whose study shows contradictory results on the use of the passive voice in experimental essays. Our comparison between the two texts shows an 
increase in passive sentences in the PDE text. The passive voice is used, moreover, when the author has to report unexpected results and the execution of particular procedures. In this respect, the PDE text differs from Newton's experiment. Newton uses the passive construction in its primary informative function of giving priority to the results obtained through the experiment As Halliday and Martin (1993: 58) have already pointed out, the passive voice is also used "in order to achieve the balance of information"] or where the subject is someone/thing other than the author. The following lines from Appendix 1 illustrate such a use:

(7) (...) if the Refraction were done regularly (p. 23: lines 14-15); that some of the incident Rays are refracted more and others less (p. 23: lines 21-22); as it were split and spread into many diverging Rays (p. 23: lines 24).

By contrast, the passive voice as it is used (more often) in the PDE text performs a different function. The authors use it to omit the subject and to list the steps followed during the experiment. Its effect is to endow the experiment with a certain neutrality and objectivity. The increasing usage of the passive voice from a diachronic point of view has already been commented on by Bazerman (1988), Halliday and Martin (1993), Atkinson (1999) and Valle (1999). Example (8) shows the use of the passive in some samples from Appendix 2.

(8) Random binary data were represented by means of (sample 3: lines 4-5); two custom lenses [...] were used (sample 3: lines 7-8); a Kodak CCD [...] was used (sample 3: lines 12-14); two different photorefractive media were used (sample 3: lines 15-16); each phase pixel was registered (sample 4: lines 7-8).

The shift from a non-abstract to a more abstract information or passivized style was described by Atkinson (1999: xxvi, 78, 126) in his study on scientific discourse from the $17^{\text {th }}$ to the $20^{\text {th }}$ century. He claims that the choice of agentless passive is a sign of modernity; a higher frequency of passive sentences in the PDE text was, therefore, to be expected.

Objectivity, the last of Boyle's principles analysed by Gotti, can also be expressed by the use of modal auxiliaries and verbs such as seem and appear when the author is unsure about the facts reported (Boyle, 1744: 197). These verbs express the author's degree of certainty (Moessner, 2006), revealing the problems and doubts that must be overcome before reaching a final result. Our survey of this feature in the two texts has yielded contrasting results. Newton's text shows a greater frequency of such elements, despite its small size; example (9) contains the occurrences found in Appendix 1. However, modals do not appear to be used as often by our PDE authors. The result for modal verbs in the PDE text compared with that obtained for Newton's text shows a striking difference. Whereas the normalized figure per 1,000 words for Newton's text is 10.0, the figure for its PDE counterpart is only 2.77 (a decline also remarked by Atkinson (1999)). Our findings regarding modality in Newton's text follow the same pattern observed by Moessner (2007) for $17^{\text {th }}$ century scientific writing generally. 
(9) might be perpendicular (p.22: line 4); might be equal (p. 23: line 5); ought to have appeared round (p. 23: line 17).

The sense of doubt in Newton's text is strengthened by his use of verbs and expressions such as seemed (p. 23: line 3), supposed (p.23: lines 16, 25) or appears (p. 23: lines 9, 18, 25, 26). As mentioned, the use of this style for the description of experiments is not found as frequently in scientific texts written today. Expressions of this kind are usually avoided, in fact, and the language is much more accurate, categorical and conclusive from the outset; our own PDE text does not contain any such verbs.

The shift from non-impersonal to impersonal style in scientific texts, as observed by Biber and Finegan (1997) and Atkinson (1999) ${ }^{7}$, is also evinced in this study. The PDE experiment shows a highly impersonal tone, in contrast with the non-impersonal tone of Newton's. Newton uses the first-person singular and a mainly active voice to describe each step of his experiment. These elements give the text a more personal, intimate tone:

(10) I held the Prism (p. 22: line 3); I looked through the Prism (p. 22: line 5); I stopt the Prism (p. 23: lines 3-4); I observed the length of its refracted Image (p. 23: lines 7-8); I removed the Prism out of the Sun's Light and looked (p. 23: lines 11-12).

\subsection{Social influences, evolution of science and conventions}

Changes in science and society will inevitably have an effect on scientific authors and the way they write their works, therefore we will attempt to see how such developments are manifested in our sample texts. For this purpose, not just Newton's books but the scientist himself can help provide us with information. Professionally, he might be defined as a conventional scientist of his time; that is, physician, chemist, mathematician, theologian and philosopher in one. Such multidisciplinarity contrasts with the tendency towards high specialisation that characterises the scientific world nowadays. Newton's reluctance to publish his works is also significant. He was already giving lectures on his investigations, lasting usually between thirty and sixty minutes, but it was not until in 1672 that Henry Oldenburg, encouraged him to present a written paper on his latest research for the Royal Society. He finally gave in to the society secretary's petition and wrote a letter which was published in Philosophical Transactions, the journal of the Royal Society (the first European scientific journal, founded by Oldenburg himself in 1665). This letter, concerning his early investigations on the reflection of light, is considered the first scientific article; the final result of that research period (1675-1687) was published as the book Opticks in 1704. However, considering that Newton was used to giving oral presentations, we cannot be certain what kind of addressee (reader or audience) he had in mind when he wrote it.

Basing ourselves on Newton's use of the active voice and the personal pronoun "I", we have assumed that the non-impersonal dimension of his text was a common feature of $18^{\text {th }}$ century experimental essays. However, an alternative explanation could also be that Newton's discourse was addressed to an expected audience and not to anonymous readers; 
certain expressions used in the text are more typically found in an oral presentation than in a paper for publication. The colloquial elements quoted in (11) and (12) could be the direct result of such orality:

(11) Then I looked through the Prism (p. 22: line 5)

(12) So then, by these two Experiments (p. 23: line 18)

Another important change that should be pointed out is the rejection of the traditional literary compositional techniques used by scientists prior to the foundation of the Royal Society (Gotti, 2001). In the $17^{\text {th }}$ century a new methodology based on observation and experimentation, known as Empiricism, was adopted and it was to prevail over the course of the century that followed. British empiricism, therefore, emerged in the $18^{\text {th }}$ century as a reaction against the rationalism of the $17^{\text {th }}$ century that maintained the origin of knowledge from innate ideas, essential concepts learnt intuitively through reason. Empiricism argued that the truth of a theory could be proved by the experience of the senses through the use of experiment and observation, and this is precisely what Newton did and described. As a kind of declaration of intentions Newton wrote on the first page of his book:

(13) My Design in this Book is not to explain the Properties of Light by Hypotheses, but to propose and prove them by Reason and Experiments.

This philosophical tendency is also supported by the vocabulary he uses: the noun experiment (p. 22: line 1; p. 23: lines 6, 25), and the verb observe (line 7). He uses an inductive methodology (from experience to conclusions) and a deductive method as the following example shows:

(14) And yet if the Refraction were done regularly according to certain Proportion of the Sines of Incidence and Refraction as is vulgarly supposed, the refracted Image ought to have appeared round (p. 23: lines 14-17)

Turning now to the verbs used in each case, we find significant differences between the two texts. While the verbs used by Newton belong to general English, that is, common verbs used in everyday life (15), the modern text uses specific verbs, belonging to a higher level of the language and more commonly found within the scientific register (16):

(15) hold (Appendix 1: p. 22, line 3); look (Appendix 1: p. 22, line 5), stop (Appendix 1: p.23, line 4), remove (Appendix 1: p. 23, lines 11-12)

(16) measure and compare (Appendix 2: sample 2, line 2); investigate (Appendix 2: sample 2, line 8); was registered (Appendix 2: sample 4, line 8).

Although both texts follow the philosophical tendency already mentioned, some structural differences are apparent. The organization of the modern text respects what is nowadays 
thought of as a logical pattern of exposition of the experimental process. It has an introduction, a description of goals and of all the instruments used, and finally the results and conclusions. Furthermore, it has been written by a research team and not one scientist working on his own; this is also a growing tendency in PDE Physical and Natural Science.

Finally, in relation to language evolution and diachronic changes in scientific writing conventions, we have observed some clear differences. One obvious change is the presence in the earlier text of certain graphemes that have disappeared in PDE, such as $\langle r\rangle$ and $<\mathrm{ct}$ ligature $>$ (examples (17) and (18) from Appendix 1):

(17) Dirtance (p. 22: line 3); arcend (p. 23: line 2)

(18) Refractions (p. 23: line 4)

Also, the use of an old form of the past inflection with the verb ftopt (p. 23: line 4) reflects that the process of standardisation of the English language was not yet complete at that time (Görlach, 1991).

Another feature of Newton's text, and of the language of the period, is the capitalisation of nouns. This particularity, present throughout the experiment, is not found in the modern text, where only acronyms and the first letter of proper nouns are capitalised. This convention faded away between the middle and the end of the $18^{\text {th }}$ century (Osselton, 1985). Aesthetic and economic reasons may have been the cause of its gradual disappearance over time.

Other important aspects of scientific writing to note are intertextuality and intratextuality. Intertextual and intratextual references were not very common in earlier writings (Valle, 1999). In fact Boyle, in his Proëmial Essay, advises against repeating the findings and opinions of others when reporting on an experiment (1744: 201). The result when we compare our texts is the inclusion of only one intertextual reference in Newton's text, against twenty such references in the modern text. Not only are the references completely different in number, so too are they in layout and content. For instance, in Newton's text when he mentions Francesco Maria Grimaldi ${ }^{8}$, the reference is limited to the scientist's surname, Grimaldo; Newton, in fact, uses a misspelled form here, owing perhaps to some confusion over its pronunciation (Appendix 1: p. 23, line 25). Neither the title of the book in question nor the year of its publication is included. Needless to say that such a reference would be unacceptable nowadays, as we can confirm if we take a look at our modern text sample (Appendix 2). Footnotes (see Appendix 2: sample 1), numbering twenty altogether, appear here from the very beginning of the article. Appendix 2 (sample 4, line 1) features one of the twenty, in which all the necessary bibliographic information is included.

The use of acronyms is a further formal point of contrast between Newton and the moderns. While the modern text includes a high number of them (example (19) shows two of them, taken from Appendix 2), such elements were not found in Newton's report. 
(19) SLM or spatial light modulator (sample 1: line 14); BER or bit-error rate (sample 2: line 10)

There were no formal guidelines to follow in Newton's time, just a few stylistic indications about scientific texts which had been given by specialists such as Bacon (Gotti, 1992). Up to then, all men of science accepted the advice of their predecessors, so we cannot expect to find a uniform expositionary behaviour in texts of this nature. As mentioned in section 3 , the first "guide" about the features that an experimental essay should contain was Boyle's Proëmial Essay, with additional suggestions found among his other works. Further style conventions for the description of experiments and scientific discovery were not to be codified until 1728, when the Royal Society finally took the necessary initiative.

\section{Conclusions}

The experimental essay was adopted by the $17^{\text {th }}$ scientific community to report on their experiments. The validity of the genre has survived down to today, and still forms an essential part of specialised writing. From a historical point of view, though, the features proposed by Boyle (Boyle, 1744; Gotti, 1996, 2001, 2003, 2005; Moessner, 2006) and the Royal Society have evolved apace with scientific writing and thought.

From our analysis of the two experimental essays selected, written at a remove of three centuries from each other, we can conclude that although both texts reflect the same philosophical ideas, the pattern and layout have clearly changed. In Newton's times there were only vague stylistic indications and Boyle's suggestions on how to write scientific texts. Newton's report does not conform to any specific structure or style and shows a high tendency to personalization. The personal tone and closeness of the writing and the presence of the scientist in the text,sharing his doubts with the reader (or hearer) are just some distinguishing features of research method in the $17^{\text {th }}$ century. It reveals that scientific discourse at the time was still far from the strict pattern adopted within the discipline today. This does mean to say that Newton's theories were simple; our analysis refers to the way in which these theories or experiments were reported. The language and style, as well as structure and methodology, are completely different, as the previous sections have shown.

The contrast between the verbs of action used by Newton and the verbs in the modern text represent an evolution in the nature of scientific exposition, as part of the progress of science generally. Newton's text has also been shown to be more in touch with the reader and his explanations are easier to understand than the process reported on in the modern experiment. By contrast, the modern increase in the use of technical vocabulary and the specialisation and depersonalisation of the language used, make the later text more difficult to understand. Most of the experiments carried out in earlier times were reported to give readers, or hearers, the opportunity to repeat them and check for themselves the discoveries made by scientists. Nowadays, the comprehensibility of scientific texts to all types of readers is not a concern, making the modern scientific text difficult even for educated 
readers if they do not have a background in the specific field required. This may be one of the reasons why we find both language and style closer to a colloquial register in the $18^{\text {th }}$ century text.

Finally, then, although both texts follow Boyle's principles of brevity, lack of assertiveness, perspicuity, simplicity of form and objectivity, the way in which the experiments are reported is slightly different. From a syntactic point of view, the text written in the $20^{\text {th }}$ century shows a consolidation of the features found in Newton's text. Thus, features such as nominalization, compounding, objectification, the use of passive voice and, in this case, the use of the language of physics, are more evident in the PDE text. On the other hand, linguistic objectivity, achieved through the use of modals and verbs like seem, appear, suppose, is clearly attested in Newton's text, yet absent in this form from the PDE text.

\section{Notes}

1. The research reported on here was funded by the Xunta of Galicia through its Dirección Xeral de Investigación e Desenvolvemento, grant number PGIDIT03PXIB10402PR (supervised by Isabel Moskowich), by the Universidade da Coruña through its Vicerreitoría de Investigación (supervised by Begoña Crespo), and by the Consellería de Innovación e Industria. These grants are hereby gratefully acknowledged.

2. The adoption of this scientific method, along with new inventions such as the telescope and the microscope, allowed scientists to develop new systematic approaches to Medicine and Natural History.

3. Isaac Newton (1642-1727) was a clear example in the field of Physics.

4. The full experiment is included in Appendix 1.

5. The samples used are taken from Appendix 2.

6 . The text chosen is taken from the COPAC catalogue. This database is supported by 24 major university research libraries in the United Kingdom and Ireland, as well as the British Library, the National Library of Scotland and the National Library of Wales.

7. Atkinson uses the terms non-abstract vs. abstract.

8. This Italian mathematician and physician discovered and explained the refraction of light in a book published in 1665 in which he attempted to formulate a theory about light waves. 


\section{References}

Atkinson, Dwight (1999): Scientific Discourse in Sociohistorical Context. The Philosophical Transactions of the Royal Society of London 1675-1975. London: Lawrence Erlbaum Associates.

BA. (2007): British Association for the Advancement of Science (http://www.the-ba.net/theba/AbouttheBA/HistoryoftheBA/index.html). (May 2007).

Banks, David (2005): "Emerging Scientific Discourse in the late Seventeenth Century. A Comparison of Newton's Opticks, and Hugyens' Traité de la Lumière”. Functions of Language 12(1): $65-86$.

Bazerman, Charles (1988): Shaping Written Knowledge. The Genre and Activity of the Experimental Article in Science. Wisconsin: University of Wisconsin Press.

Biber, Douglas and Edward Finegan (1997): "Diachronic Relations among Speech-Based and Written registers in English". In Tertu Nevalainen and Leena Kahlas-Tarkka, eds., To explain the Present. Studies in the Changing English Languages in Honour of Matti Rissanen. Helsinki: Société Néophilologique, 253-275.

Boyle, Robert (1744): The Works of the Honourable Robert Boyle. In five volumes to which is prefixed the life of the author. Vol I. London: printed for A. Millar. (Eighteenth Century Collection Online)

Birch, Thomas (1756): The History of the Royal Society of London for Improving of Natural Knowledge, from its First Rise. Vol. I. London: A. Millar. (Eighteenth Century Collection Online).

Bunch, Bryan and Alexander Hellemans (2004): The History of Science and Technology. Boston/ New York: Houghton Mifflin Company.

Day, Robert (2006): How to Write and Publish a Scientific Paper. Cambridge: Cambridge University Press.

Ebel, Hans (2004): The Art of Scientific Writing from student reports to professional publications in Chemistry and related Fields. Weimhem: WILEY-VCH.

Fulton, John F. (1932): "Robert Boyle and his Influence on Thought in the Seventeenth Century". Isis 18: 77-102.

Görlach, Manfred (1991): Introduction to Early Modern English. Cambridge: Cambridge University Press.

Gotti, Maurizio (1992): “The Development of a Scientific Language in the $17^{\text {th }}$ Century". In Carmela Nocera Avila, Nicola Pantaleo and Dominico Pezzini, eds., Early Modern English: Trends, Forms and Texts. Fasano: Schena editore, 319-343. . (1996): Robert Boyle and the Language of Science. Milano: Guerini Scientifica. . (2001): “The Experimental Essay in Early Modern English". European Journal of English Studies 5(2): 221-139.

. (2003): Specialized Discourse. Linguistic Features and changing Conventions. Bern: Peter Lang.

(2005): Investigating Specialized Discourse. Bern: Peter Lang.

Hall, A. Rupert (1981): From Galileo to Newton. New York: Dover.

Halliday, Michael A. K. and James R. Martin (1993): Writing Science. Pittsburgh: University of Pittsburg Press.

Honeybone, Michael (2005): "Sociability, Utility and Curiosity in the Spalding Gentlemen's Society, 1710-60". In David Knight and D. Matthew Eddy, eds., Science and Beliefs. From 
Natural History to Natural Science 1700-1900. Hampshire: Ashgate: 63-75.

Hunter, Michael (2007): "Robert Boyle and the Early Royal Society: a reciprocal Exchange in the Making of Baconian Science". BJHS 40: 1-23.

Moessner, Lilo (2006): "The Birth of the Experimental Essay". In Vijay Bathia and Maurizio Gotti, eds., Explorations in Specialized Genres. Bern/Berlin: Peter Lang: 59-77. . (2007): "How Representative are the Philosophical Transactions of the Royal Society of $17^{\text {th }}$ Century Scientific Writing?". Paper presented at the ICAME Conference. . (forthcoming-a): "Variation and Change in the Writings of $17^{\text {th }}$ Century Scientists". . (forthcoming-b): "The Influence of the Royal Society on $17^{\text {th }}$ Century Scientific Writing".

Osselton, Noel (1985): "'Spelling-book Rules and the Capitalization of Nouns in the Seventeenth and Eighteenth Centuries". In Mary-Jo Arn and Hanneke Wirtjes, eds., Historical and editorial studies in medieval and modern English:for Johan Gerritsen. Groningen: Wolters-Noordhoff, 49-61.

Peat, Jennifer, et al. (2002): Scientific Writing easy when you know how. London: BMJ.

Perelman, Lesli C. et al. (1997): The Mayfield Handbook of Technical and Scientific Writing. McGraw-Hill Humanities. (http://www.mhhe.com/mayfieldpub/tsw/ home.htm).

Rissanen, Matti (1999): "Syntax". In Roger Lass, ed., The Cambridge History of the English Language, vol. III: 1476-1776. Cambridge: Cambridge University Press, 187-331.

Shapin, Steven (1984): "Pump and Circumstance. Robert Boyle Literary Technology". Social Studies of Science 14(4): 481-520.

Shapiro, Alan (2004): “Newton's Experimental Philosophy". Early Science and Medicine 9(3): 185217.

Shulman, E. Robert (1996): “How to write a scientific paper”. Annals of Improbable Research 2/5 (http://improbable.com/magazine).

Spalding Gentlemen's Society (2007): (http://www.spalding-gentlemens-society.org/) (May 2007). Sprat, Thomas (1722): The History of the Royal Society of London, for the Improving of Natural Knowledge. London: printed for Samuel Chapman (Eighteenth Century Collection Online).

Tischler, Marc (2006): Scientific Writing Booklet (http://www.biochem.arizona. edu/marc/SciWriting.pdf).

Valle, Ellen (1999): A Collective Intelligence. The Life Sciences in the Royal Society as a Scientific Discourse Community, 1665-1965. Turku: University of Turku.

\section{Appendix 1.}

Newton, I. 1704. Opticks

http://dibinst.mit.edu/BURNDY/Collections/Babson/OnlineNewton/NewtonianPDF/Opticks/O pticks1704.pdf (2 April 2004) 


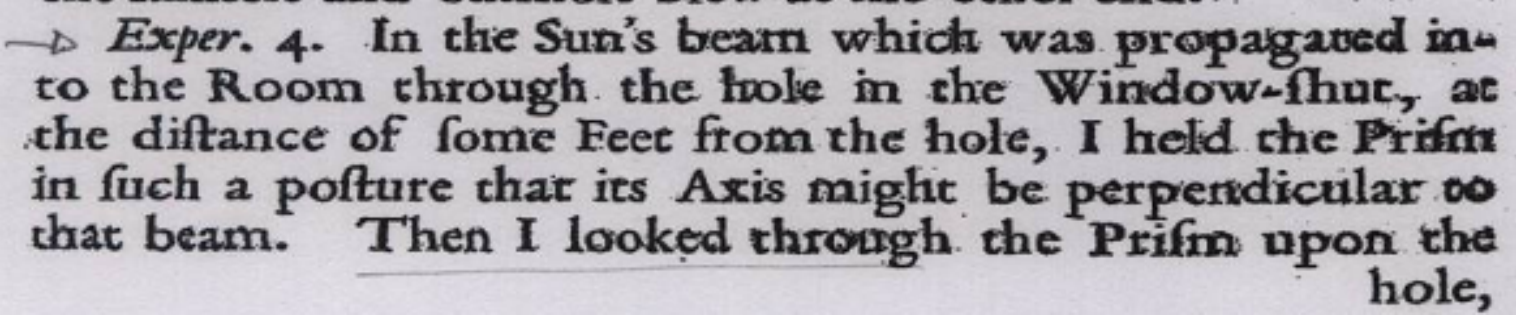

\section{[23]}

hole, and turning the Prifm to and fro about its Axis to make th'e Image of the hole afcend and defcend, when between its two contrary Motions it feemed ftationary, I ftopt the Prifm that the Refractions on both fides of the refracting Angle might be equal to each other as in the former Experiment. In this Situation of the Prifm viewing through it the faid hole, I obferved the length of its refracted Image to be many times greater than its breadth, and that the moft refracted part thereof appeared violet, the leaft refracted red, the middle parts blew green and yellow in order. The fame thing happened when I removed the Prifm out of the Sun's Light, and looked through it upon the hole fhining by the Light of the Clouds beyond it. And yet if the Refraction were done regularly according to one certain Proportion of the Sines of Incidence and Refraction as is vulgarly fuppofed, the refracted Image ought to have appeared round.

So then, by thefe two Experiments it appears that in equal Incidences there is a confiderable inequality of Refractions : But whence this inequality arifes, whecher it be that fome of the incident Rays are refracted more and others lefs, conftantly or by chance, or that one and the fame $\mathbf{R}$ ay is by Refraction difturbed; fhattered, dilated, and as it were fplit and fpread into many diverging Rays, as Grimaldo. fuppofes, does not yet appear by thefe Experi- 25 ments, but will appear by thofe that follow.

Exper. 5. Confidering therefore, that if in the third Experiment the Image of the Sun thould be drawn out into. an oblong form, either by a Dilatation of every $\mathbf{R} a y$, or by any other cafual inequality of the Refractions, the fame: 30 oblong Image would by a lecond Refraction made Sideways be drawn out as much in breadth by the like Dilatation of the Rays or other cafual inequality of the Refractions. 


\section{Appendix 2}

Bernal, María-P., Geoffrey W. Burr, Hans Coufal, John A. Hoffnagle, C. Michael Jefferson, Roger M. Macfarlane, Robert M. Shelby, and Manuel Quintanilla (1998): "Experimental study of the effects of a six-level phase mask on a digital holographic storage system”. Applied Optics, Vol. 37, No. 11: 2094-2101 (http://ao.osa.org/search.cfm).

SAMPLE 1 (P. 2095)

1.Introduction
Holographic data storage was first proposed in
the early 1960's. Much effort has recently been
put into its development because of the potential
to provide a fast readout rate and high
capacity. ${ }^{1-8}$ These capabilities come about
through the multiplexing of two-dimensional
pixel arrays with a data rate of up to 1 Gbit/sec.

SAMPLE 2 (P. 2096)

1 Making use of the holographic storage tester described earlier, 7 we measure and compare the three configurations mentioned above: recording in the Fourier transform plane with no phase

5 mask or with a six-level phase mask and recording away from the Fourier transform plane. We investigate the dynamic-range performance by measuring the $\mathrm{M}$ \# for different object-reference intensity ratios, as well as the 10 bit-error rate (BER) degradation (using global thresholding of the three configurations versus the object-beam exposure. 
SAMPLE 3 (P. 2096)

SAMPLE 4 (P. 2096)

\section{Experimental Setup}

1 The input data page was a chrome-on-glass transmission mask containing a two-dimensional array of 256 X 256 pixels with a 36-um linear dimension and $100 \%$ fill factor. Random binary data

5 were represented by means of setting approximately half the pixels to ON and the other half to OFF. Two custom lenses, each with an effective focal length of $89 \mathrm{~mm}$, were used to implement the $4 f$ system. The excellent optical performance of the tester permits

10 pixel-to-pixel matching of the input data page to the detector array. A Kodak CCD with 1536 X 1024 pixels and 9-um pixel spacing integrated into a Princeton Instruments Model ST138 camera was used.

15 For the experiments two different photorefractive media were used: a $15 \mathrm{~mm} \mathrm{X} 15 \mathrm{~mm} \mathrm{X} 8 \mathrm{~mm}$ $\mathrm{LiNbO}_{3}$ : Fe crystal and a $9.8 \mathrm{~mm} \mathrm{X} 9.8 \mathrm{~mm} \mathrm{X} 9.8$ $\mathrm{mm}$ SBN:Ce crystal. To achieve maximum recording we used two standard geometries. The

$20 \mathrm{LiNbO}_{3}: \mathrm{Fe}$ crystal was used in $90^{\circ}$ geometry with the $c$ axis at $45^{\circ}$ to the object and reference beams. The molar dopant concentration was $0.02 \%$, and the absorptivity of the crystal at a wavelength of 514.5 $\mathrm{nm}$ was $0.8 \mathrm{~cm}^{-1}$.

1 The phase mask was a six-level phase plate $^{16}$ fabricated by means of writing with a laser on a substrate coated with photoresist. The substrate on which the phase mask was written was also 5 antireflection coated before writing the phase mask. This phase mask was composed of a 256 X 256 array of linear 36-um pixels. [...] Each phase pixel was registered with the corresponding amplitude pixel in the data mask to avoid errors in the retrieval of the

10 data page caused by diffraction effects coming from the edges of the phase pixels. When the phase mask was imaged carefully on the data-mask plane, every data pixel contained a constant random phase (from the corresponding phase pixel).

16. Q. Gao and R. Kostuk, "Improvement to holographic digital data-storage systems with random and pseudorandom phasemasks," Appl. Opt. 36, 4853- 48611997. 